OPEN ACCESS

Edited by:

Praveen K. Mishra,

Wadia Institute of Himalayan Geology,

India

Reviewed by:

Xiaodong Miao,

Linyi University, China

Kizhur Sandeep,

Central University of Kerala, India

*Correspondence:

Shenliang Chen

slchen@sklec.ecnu.edu.cn

Specialty section:

This article was submitted to

Quaternary Science, Geomorphology and Paleoenvironment,

a section of the journal

Frontiers in Earth Science

Received: 01 April 2021 Accepted: 18 August 2021 Published: 30 August 2021

Citation:

Lyu W, Fu T, Hu Z, Tang YZ, Chen G, Xu X, Chen $Y$ and Chen S (2021) Sedimentary Dynamics of the Central South Yellow Sea Revealing the Relation Between East Asian Summer and Winter Monsoon Over the

Past 6000 years.

Front. Earth Sci. 9:689508. doi: 10.3389/feart.2021.689508

\section{Sedimentary Dynamics of the Central South Yellow Sea Revealing the Relation Between East Asian Summer and Winter Monsoon Over the Past 6000 years}

\author{
Wenzhe Lyu $u^{1,2}$, Tengfei $\mathrm{Fu}^{2,3}$, Zhangxi Hu${ }^{4}$, Ying Zhong Tang ${ }^{4}$, Guangquan $\mathrm{Chen}^{2,3}$, \\ Xingyong $\mathrm{Xu}^{2,3}$, Yanping Chen ${ }^{5}$ and Shenliang Chen ${ }^{1 *}$
}

${ }^{1}$ State Key Laboratory of Estuarine and Coastal Research, East China Normal University, Shanghai, China, ${ }^{2}$ Key Laboratory of Marine Geology and Metallogeny, First Institute of Oceanography, Ministry of Natural Resources, Qingdao, China, ${ }^{3}$ Laboratory of Marine Ecology and Environmental Science, Qingdao National Laboratory for Marine Science and Technology, Qingdao, China, ${ }^{4}$ CAS Key Laboratory of Marine Ecology and Environmental Sciences, Institute of Oceanology, Chinese Academy of Sciences, Qingdao, China, ${ }^{5}$ Key Laboratory of Engineering Oceanography, Second Institute of Oceanography, Ministry of Natural Resources, Hangzhou, China

The mud areas of East Asian marginal seas record considerable information about regional environmental evolution. However, debate continues regarding the relative importance of the major factors in regional sedimentary dynamics, i.e., the East Asian summer monsoon, East Asian winter monsoon, and oceanic circulation. In this study, we investigated the characteristics of grain size from a gravity core obtained in the South Yellow Sea to reveal changes in sedimentary dynamics since 6,000 years BP, and to elucidate the relationship between the East Asian summer monsoon and the East Asian winter monsoon. We found that the mean grain size was in the range of 6.9-7.8 $\Phi$, the sediment was poorly sorted within a small range $(1.2,1.5)$, and the $M$ values from 4.7 to $6.7 \mu \mathrm{m}$ and most of the $C$ values from 24 to $65 \mu \mathrm{m}$ suggested pelagic suspension transport. Results indicated that the intensity of both the East Asian summer monsoon and the East Asian winter monsoon showed a fluctuating trend of decrease after approximately 6,000 years BP, and that the relationship between them was generally anticorrelated. Based on these results, we suggest that positive correlation between the East Asian summer monsoon and the East Asian winter monsoon usually results in the fall or establishment of ancient dynasties in the Central Plains of China and that negative correlation between them is controlled by strong solar radiation. Weakening of solar radiation diminishes its control of the intensity of (and thus the correlation between) the East Asian summer monsoon and the East Asian winter monsoon, at which time the North Atlantic Oscillation plays a modulating role.

Keywords: South Yellow Sea (SYS), continental mud area, sedimentary evolution, East Asian Winter Monsoon (EAWM), East Asian Summer Monsoon (EASM) 


\section{HIGHLIGHTS}

1) Trends for the EASM and the EAWM and for their relationship since 6,000 years BP were extracted.

2) Negative correlation between the EASM and the EAWM is controlled by strong solar radiation.

\section{INTRODUCTION}

In recent years, the South Yellow Sea (SYS) has become an area of active research for paleoclimate, sedimentary environment, and marine current/hydrodynamics studies (Kong et al., 2006; Xiang et al., 2008; Zhao et al., 2013; Liu et al., 2014; Yang et al., 2018; Zhang et al., 2018; Wang et al., 2019). As a typical shelf sea, the SYS is an important reservoir of and transportation channel for sediments from the Yellow River, Yangtze River, and some local rivers. It has the largest area of mud in the shelf area of the eastern China Seas, and its sediments are sensitive to changes of sea level and climate (Yang and Youn, 2007). Many studies have shown that the volume of river input into the SYS is determined mainly by precipitation that is controlled by the East Asian summer monsoon (EASM) (Dykoski et al., 2005; Ding et al., 2008; Hu et al., 2008; Zhou et al., 2012). Recent studies have also revealed that the modern circulation system of the SYS, which largely comprises the Yellow Sea Warm Current (YSWC) and the Yellow Sea Coastal Currents (YSCC), was established approximately 6,000 years BP and that it has a relationship with the East Asian winter monsoon (EAWM) (Yuan and Hsueh, 2010; Xing et al., 2012; Zhao et al., 2013). Therefore, studies on the sediment sources and current systems of the SYS are actually linked to the East Asian monsoon (EAM).

The EAM climate system is an important component of the global climate system. Thus, further study of the patterns and forcing mechanisms associated with the EAM will help explain global climate change. Previous studies have used multiple proxies archived in lakes (Yancheva et al., 2007; Li et al., 2015; Li et al., 2018), peat (Hong et al., 2001; Hong et al., 2009), stalagmites (Hu et al., 2008; Wang K. et al., 2008; Cheng et al., 2019; Liu et al., 2020), ice cores (Thompson, 1997), and loess (Sun et al., 2006; Song et al., 2014; Beck et al., 2018) to reveal the longterm change of the EAM system and its effects. With the extension of the research effort toward the ocean, the extraction of EAM information from continental shelves has increased (Wang Y. et al., 2008; Zheng et al., 2010; Qiao et al., 2011; Hu et al., 2012; Zhou et al., 2012) and the most extensive proxy is the grain size of shelf sediment. However, it remains to be confirmed whether the winter monsoon or the summer monsoon is the dominant factor controlling grain size. For example, Xiao et al. (2006) used the sensitive grain size from the mud area of the inner shelf of the East China Sea to reconstruct a high-resolution record of the EAWM. Qiao et al. (2011) used the key grain size component from the East China Sea to reconstruct the record of the late Holocene EAWM. Hu et al. (2012) suggested that the grain size parameters of cores from the central mud area of the SYS are controlled mainly by the EAWM, and thus they recurved the variations of the EAWM since the middle Holocene.

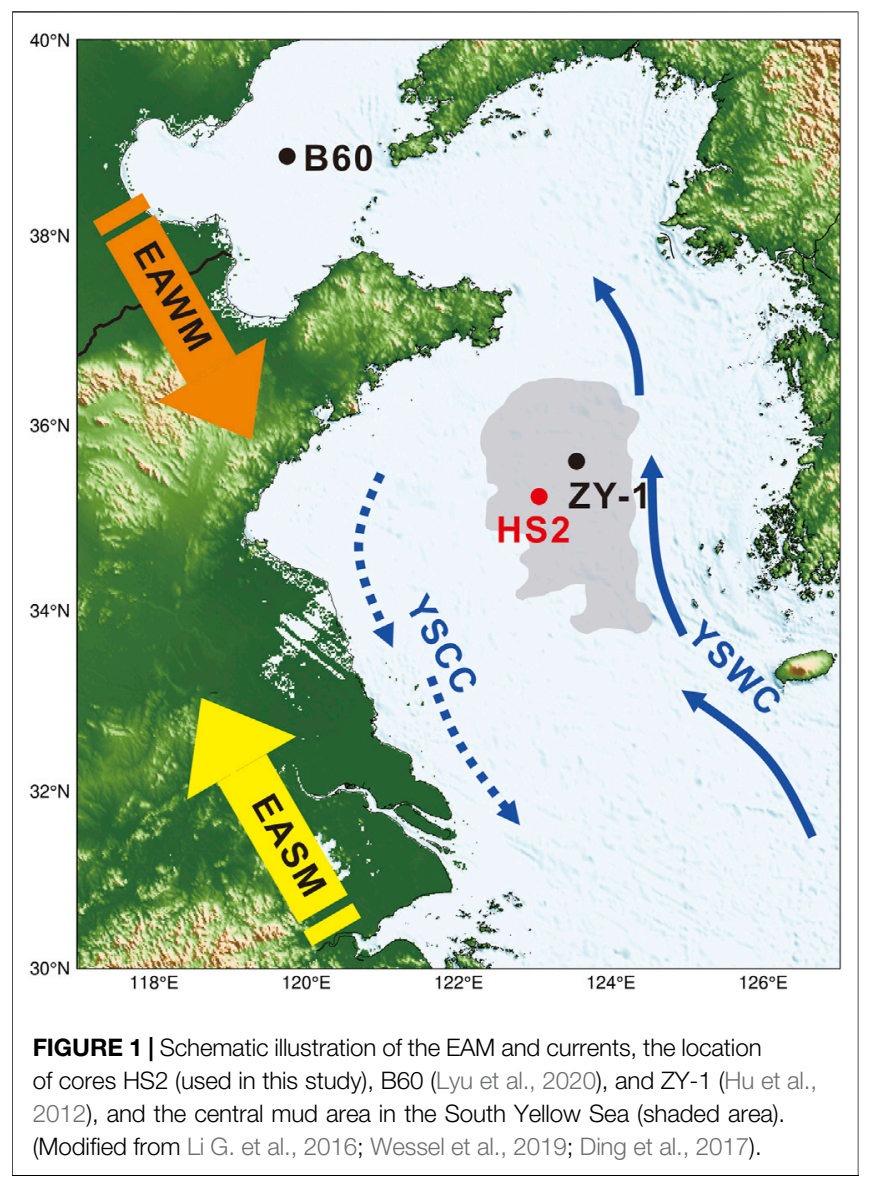

However, Wang Y. et al. (2008) suggested that the mean grain size of a sediment core obtained from the inner shelf of the East China Sea had no direct link to the EAWM, but that the rate of deposition exhibited a trend consistent with the EASM. Based on high-resolution magnetic analysis, Zheng et al. (2010) also believed that the sediment from the same core contains information relating to the EASM. Zhou et al. (2012) found that the sedimentary characteristics of a sediment core from the mud area of the Northern Yellow Sea correlated well with spatially averaged precipitation around the Yellow River, which could serve as reasonable proxies for summer monsoon strength. Therefore, it is necessary to confirm the role of EASM and EAWM in the sediment change.

It is also important to investigate the relationship between EASM and EAWM. Previous studies have shown that the EAM has an important impact on East Asia, especially China, and that there is negative correlation between the EAWM and temperature in winter and positive correlation between the EASM and precipitation in summer ( $\mathrm{Wu}$ and Chan, 2005; Huang et al., 2007; Ding et al., 2008; Ding et al., 2009; Li and Wang, 2012). Thus, strong positive correlation often results in an anomalously strong or weak EASM and EAWM, which can lead to serious flood and drought disasters in different regions of China (Ding et al., 2008; Ding et al., 2009).

The nature of the relationship between the EASM and the EAWM during the Holocene remains controversial (Xiao et al., 

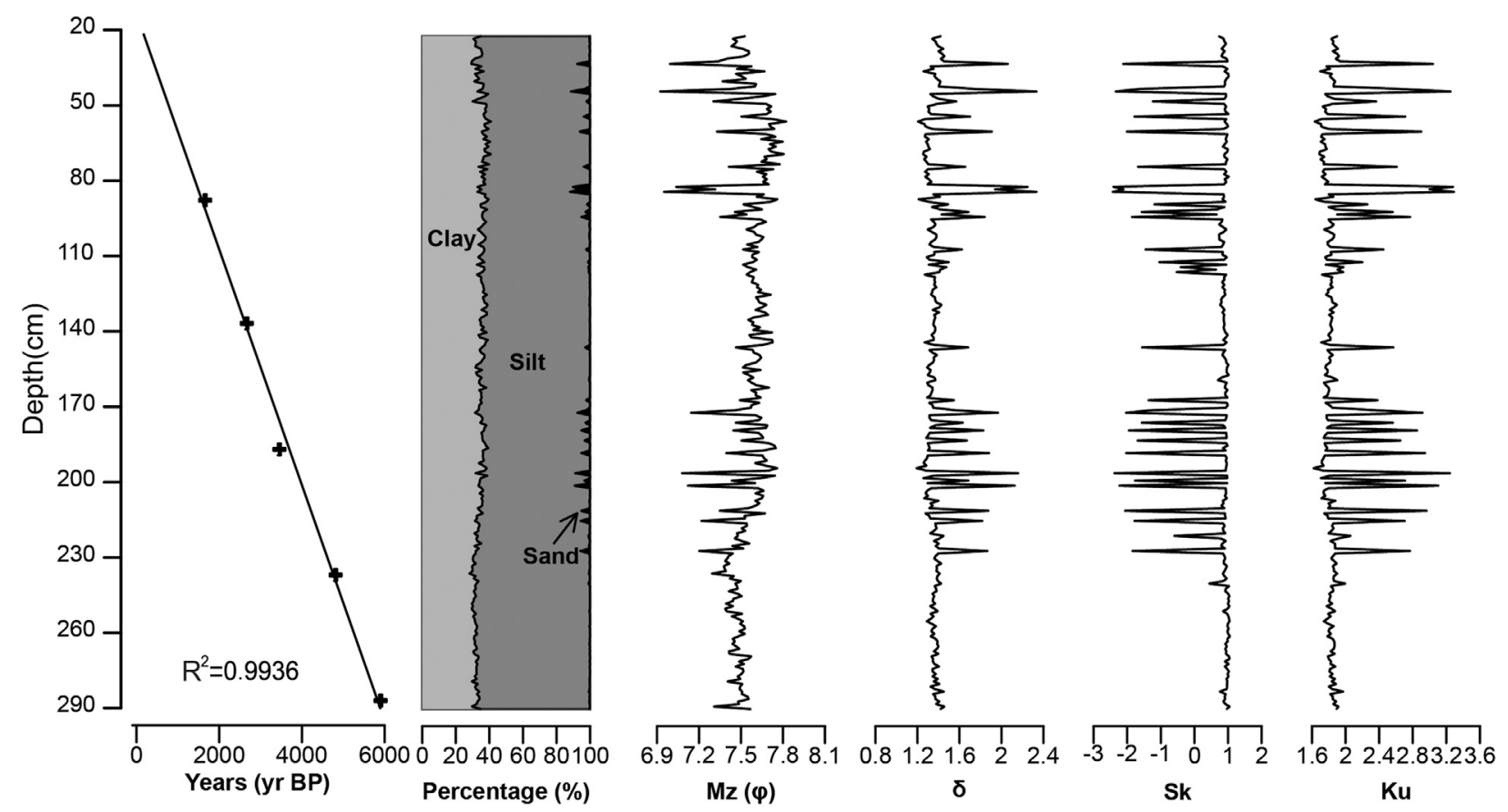

FIGURE 2 | Age model and profiles of core HS2 with grain size changes: clay, silt, and sand content, mean grain size, sorting, skewness, and kurtosis.

2006; Yancheva et al., 2007; Zhang and Lu, 2007; Zhou and Zhao, 2009; Steinke et al., 2011; Ge et al., 2017), although antiphase correlation has been identified on orbital timescales (Ding et al., 1995). The main reasons for ambiguity could include dating issues, the extraction of proxies, and different resolutions used in different studies. Therefore, it is vital to document monsoonal variability from different sedimentary sequences to clarify the factors controlling sedimentation on the continental shelves of the SYS, and thus to elucidate the relationship between the EASM and the EAWM.

In the current study, we analyzed the sediment grain size of core HS2, which was obtained in the central mud area of the SYS, and we reconstructed the EASM and EAWM records in the SYS for the period since 6,000 years BP. Based on the results, the dominant sedimentary dynamics within the study area and the relationship between the EASM and the EAWM were investigated.

\section{MATERIALS AND METHODS}

\section{Core HS2}

The studied core (HS2) was collected from the central mud area of the SYS $\left(35^{\circ} 30.0^{\prime} \mathrm{N}, 122^{\circ} 59.9^{\prime} \mathrm{E}\right.$; water depth: $\left.88 \mathrm{~m}\right)$ in September 2015 during a research cruise of the R/V DONG FANG HONG ER HAO (Figure 1), which was organized by the National Natural Science Foundation of China. The length of core obtained from the drill site was $290 \mathrm{~cm}$, and the section of $22-290 \mathrm{~cm}$ below the core top, which was undisturbed and well constrained by radiocarbon dating, was selected for this study.
This $269-\mathrm{cm}$-thick interval was sampled into $1-\mathrm{cm}$ sections for analyses that included accelerator mass spectrometry (AMS) ${ }^{14} \mathrm{C}$ dating and sediment grain size measurements.

\section{Age Model}

Five foraminiferal samples were collected for AMS ${ }^{14} \mathrm{C}$ dating at the Beta Analytic Radiocarbon Dating Laboratory, Miami, United States. We converted the radiocarbon ages to calibrated calendar ages using the Calib 7.0 program (Stuiver and Reimer, $1993)$ and by applying the regional marine reservoir effect $(\Delta R$ value $=-81 \pm 60$ years $)$ chosen from the Marine Reservoir Correction Database (Table 1).

The age-depth correlation for the core record is shown in Figure 2. According to Qiao et al. (2017), the average modern sedimentation rate of the central Yellow Sea mud area is $1.4 \mathrm{~mm} /$ year, and that the mixed section of our core from 0 to $22 \mathrm{~cm}$ might have accumulated over approximately 157 years. Comparison of the modern sedimentation rate ages at the depth of $13 \mathrm{~cm}$ (1950 AD or 0 year BP) with the age at the same level determined from interpolation between the five AMS

${ }^{14} \mathrm{C}$ dates suggests that the radiocarbon age is in excess of the modern sedimentation rate age by 500 years. In consideration of both the benthic foraminiferal effect and the reservoir effect on the measurements of bulk organic carbon, we subtracted a value of 500 years from all ${ }^{14} \mathrm{C}$ ages prior to calibration.

\section{Sediment Grain Size}

In all, 269 grain size samples were measured at 1-cm intervals. An amount of approximately $0.5 \mathrm{~g}$ of material was collected from each sample, which was then pretreated with both a $10-20 \mathrm{ml}$ 

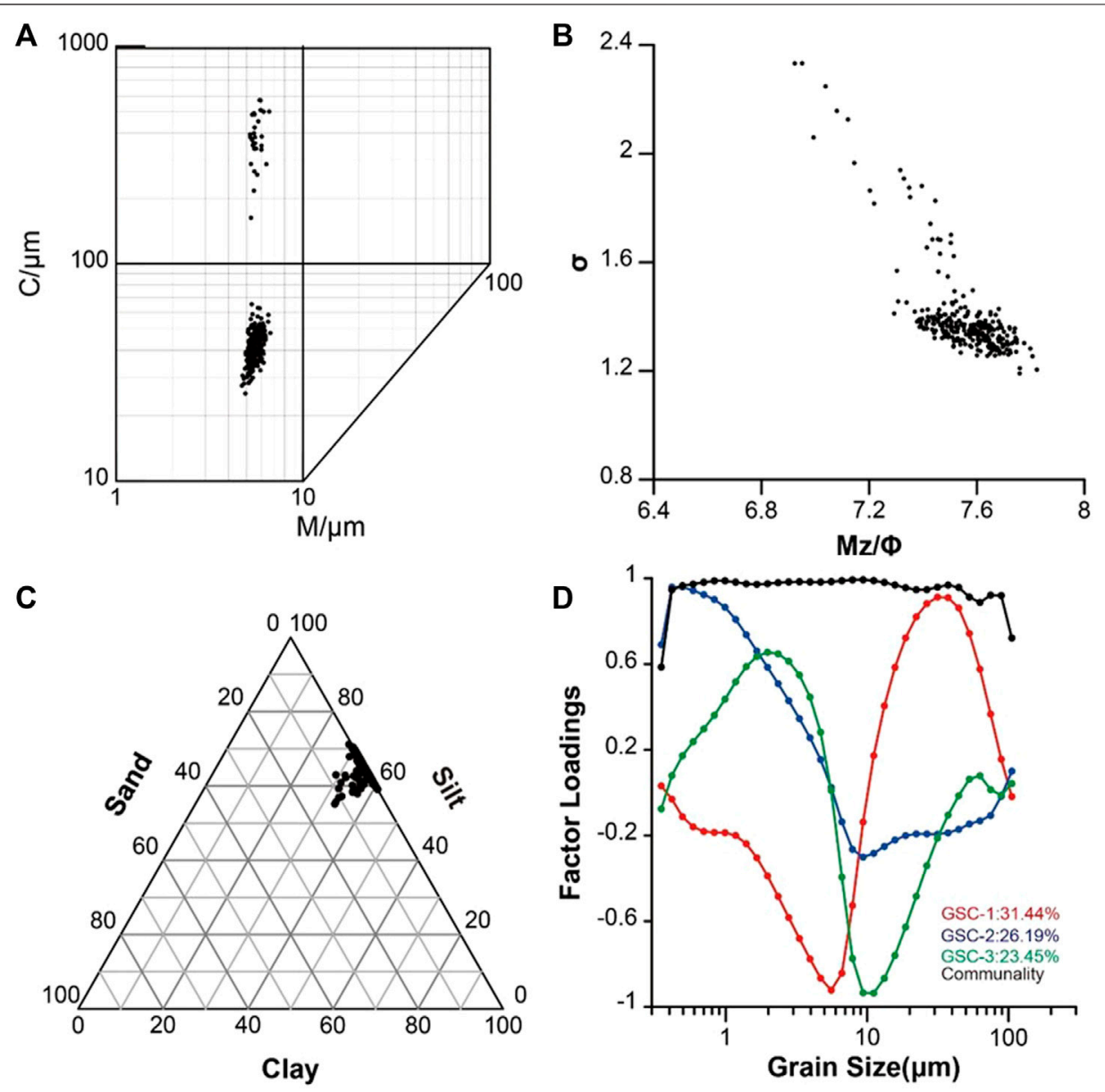

FIGURE 3 | Sediment grain size analysis of core HS2 samples: (A) relationship between $\mathrm{C}$ (the one percentile) and M (the median diameter), (B) relationship between mean grain size (represented by Mz, $\Phi$ values) and sorting (represented by $\sigma$, nondimensional parameters), (C) ternary diagrams for clay, silt, and sand components, and (D) VPCA results of core HS2

$\mathrm{H}_{2} \mathrm{O}_{2}$ solution (30\%) to remove organic matter and a $10 \mathrm{ml} \mathrm{HCl}$ solution (10\%) for $12 \mathrm{~h}$ to remove carbonates. Prior to measurement, all samples were rinsed with deionized water in a centrifuge at a rotation speed of $4,000 \mathrm{rpm}$ and dispersed by ultrasonic treatment over a 10 -min period. Measurements were obtained using a Malvern Mastersizer 2000 laser particle size analyzer (Malvern Panalytical Ltd., United Kingdom) at the Key Laboratory of Marine Sedimentology and Environmental Geology, First Institute of Oceanography, MNR. Fifty grain size classes in the range $0.3-2000 \mu \mathrm{m}$ were selected for further analysis.

\section{RESULTS AND ANALYSES}

We chose the moment method of McManus (1988) to calculate grain size parameters, including mean grain size $(\mathrm{Mz})$, sorting $(\sigma)$, skewness (Sk), and kurtosis ( $\mathrm{Ku})$, as follows:

$$
\text { mean grain size : } M z=\frac{\sum f m_{\phi}}{100},
$$

$$
\begin{aligned}
& \text { sorting : } \sigma=\sqrt{\frac{\sum f\left(m_{\phi}-M z\right)^{2}}{100}}, \\
& \text { skewness : SK }=\frac{\sum f\left[m_{\phi}-M z\right]^{3}}{100 \sigma^{3}}, \\
& \text { kurtosis : } K u=\frac{\sum f\left[m_{\phi}-M z\right]^{4}}{100 \sigma^{4}},
\end{aligned}
$$

where $m_{\Phi}$ represents grain size (unit: $\left.\Phi\right), f$ represents the percentage content of each grain grade, $\sum f=100$, and $\sigma, \mathrm{Sk}$, and $\mathrm{Ku}$ are nondimensional parameters.

In addition, we selected one coupled parameter, i.e., the C-M pattern (Passega, 1957; 1964), where the one percentile $\mathrm{C}$ reflects the initial hydrodynamic energy and the median diameter $M$ reflects the average hydrodynamic energy.

As a result, the range of $\mathrm{Mz}$ was 6.9-7.8 $\Phi$, most of which was between 7.4 and $7.8 \Phi$, and the material was poorly sorted within a small range $(1.2,1.5)$ (Figures 2, 3B). There was negative correlation between $\mathrm{Mz}$ and $\sigma$, which could be divided into two parts with different slopes (Figure 3B). For most samples, 

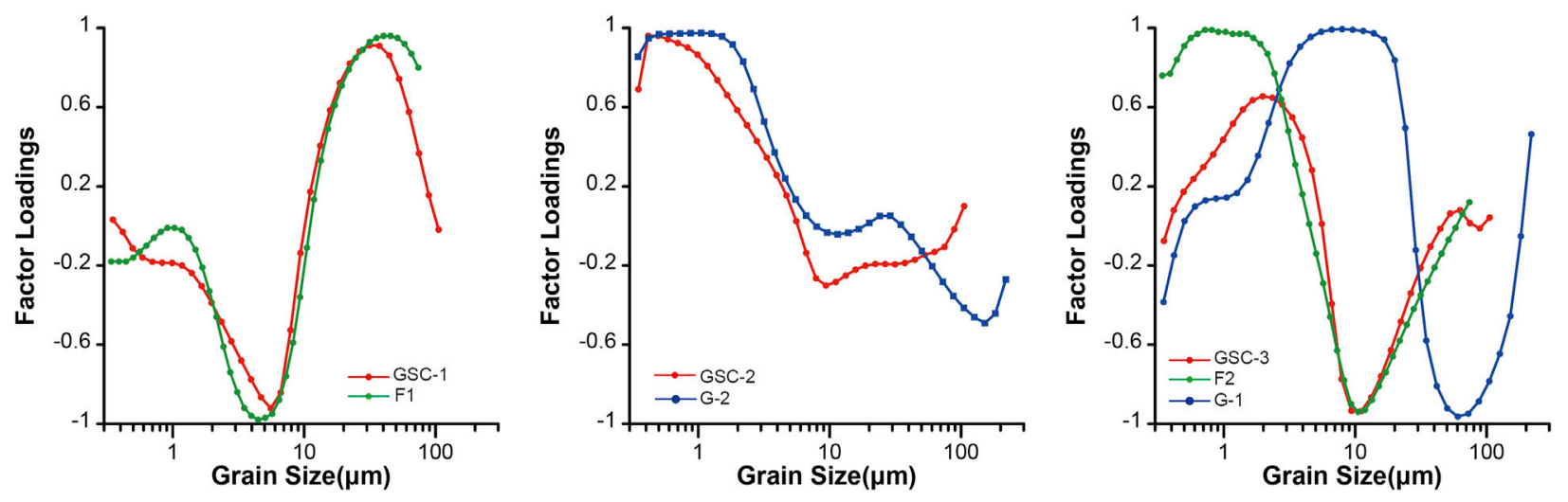

FIGURE 4 | VPCA results from different types of samples: GSC-1, GSC-2 and GSC-3 of core HS2 (this study), F1 and F2 of core ZY-1 (Hu et al., 2012 ) and G-1 and G-2 of core B60 (Lyu et al., 2020).

sediment sorting improved slowly with the decrease of $\mathrm{Mz}$. The values of $\mathrm{Sk}$ and $\mathrm{Ku}$ were largely in the range of $0.6-1.0$ and 1.5-1.9, respectively (Figure 2), indicating that the samples had positive skewness and normal kurtosis. The contents of silt (55-70\%) and clay (30-40\%) particles changed little, while the content of sand particles was mostly $<1 \%$, except for a small number of layers in which it was $<10 \%$ (Figures 2, 3C). As shown in the ternary diagrams and parameter scatter plots (Figure 3C), the sedimentary environment was reasonably stable with no significant change.

The C-M pattern is useful for analyzing both the mode of sediment transport and the hydrodynamic intensity. As shown, the $\mathrm{M}$ values from 4.7 to $6.7 \mu \mathrm{m}$ indicate that the average hydrodynamic energy was stable and weak, while the $C$ values varied widely from 25 to $600 \mu \mathrm{m}$ (Figure 3A). Most points are located in a small area in which the $\mathrm{C}$ values are in the range of 25-65 $\mu \mathrm{m}$ (Figure 3A), indicating that the initial hydrodynamic energy was weak. However, the $\mathrm{C}$ values in the range of $125-600 \mu \mathrm{m}$ indicate a wide range of unstable initial hydrodynamic energy, which might be related to a change of sediment source or to a highly dynamic sedimentary event. According to Passega $(1957,1964)$, the points located in the range of $25-65 \mu \mathrm{m}$ suggest pelagic suspension transport. These results showed that the sedimentary environment was reasonably stable, and the sediments can be used to extract paleoenvironmental information.

For further analysis of grain size, we used a varimax-rotated principal component analysis (VPCA) method based on a correlation matrix for grain size spectra. Because the content of grain sizes $>105.6 \mu \mathrm{m}$ is usually $<0.01 \%$, we extracted 34 grain size classes in the range of $0.3-105.6 \mu \mathrm{m}$ for the VPCA. Three components extracted from the VPCA procedure, i.e., GSC-1, GSC-2, and GSC-3, accounted for $81.08 \%$ of the total variance (Figure 4D). GSC-1 (31.44\% of the data variance) consisted of two groups (2.8-7.9 and 15.8-62.8 $\mu \mathrm{m}$ ), of which the fine part and the coarse part provided high negative and positive loading, respectively. Conversely, for GSC-2 $(26.19 \%$ of the data variance) and GSC-3 (23.45\% of the data variance), the fine part (GSC-2: 0.35-1.97 $\mu \mathrm{m}$, GSC-3: 1.18-3.32 $\mu \mathrm{m}$ ) and the coarse part (GSC-2: 7.88-13.24 $\mu \mathrm{m}$, GSC-3: 7.88-18.72 $\mu \mathrm{m}$ ) provided positive and negative loading, respectively.

To integrate the information on various sedimentary dynamics, we obtained a new series (i.e., GSC-23) according to the data variance of GSC-2 and GSC-3:

$$
\text { GSC }-23=\text { GSC }-2 \times 26.19+\text { GSC }-3 \times 23.45
$$

\section{DISCUSSION}

\section{Variability of the East Asian Monsoon}

For the study of the EAM, a reliable information carrier is crucial. Generally, fine-grained sediments can be used as an effective carrier, but the premise is that their sedimentary records are complete, continuous and can be extracted smoothly. The temporal variability of grain size parameters, along with C-M pattern, ternary diagrams, and the relationship between sorting and mean grain size, confirms a relatively stable depositional environment (Figures 2, 3A-C-C). Thus, the sediments from core HS2 are well-suited for extracting paleoenvironmental information, e.g., monsoonal variability, sedimentary dynamics.

Based on previous studies (Yang et al., 2003; Yang and Youn, 2007; Zhou et al., 2015), it is known that the development of the mud area in the SYS is affected primarily by oceanic currents and the supply of sediment, both of which have obvious seasonal differences. In combination with the VPCA results shown in Figure 3D, i.e., the different loadings of fine and coarse particles between GSC-1, GSC-2, and GSC-3, we infer that GSC-2 and GSC-3 mostly represent the influence of weaker hydrodynamic conditions in summer, when the change of grain size is controlled principally by sediment supply. Conversely, GSC-1 most likely reflects the sedimentary processes in winter, when the study area is influenced primarily by the YSCC and YSWC.

It is usually considered that finer sediments on the continental shelves of East Asian marginal seas can be used as a proxy for the EASM because sediments dominated by the EAWM are relatively coarser. For example, the median grain size $(8-14 \mu \mathrm{m})$ of core 

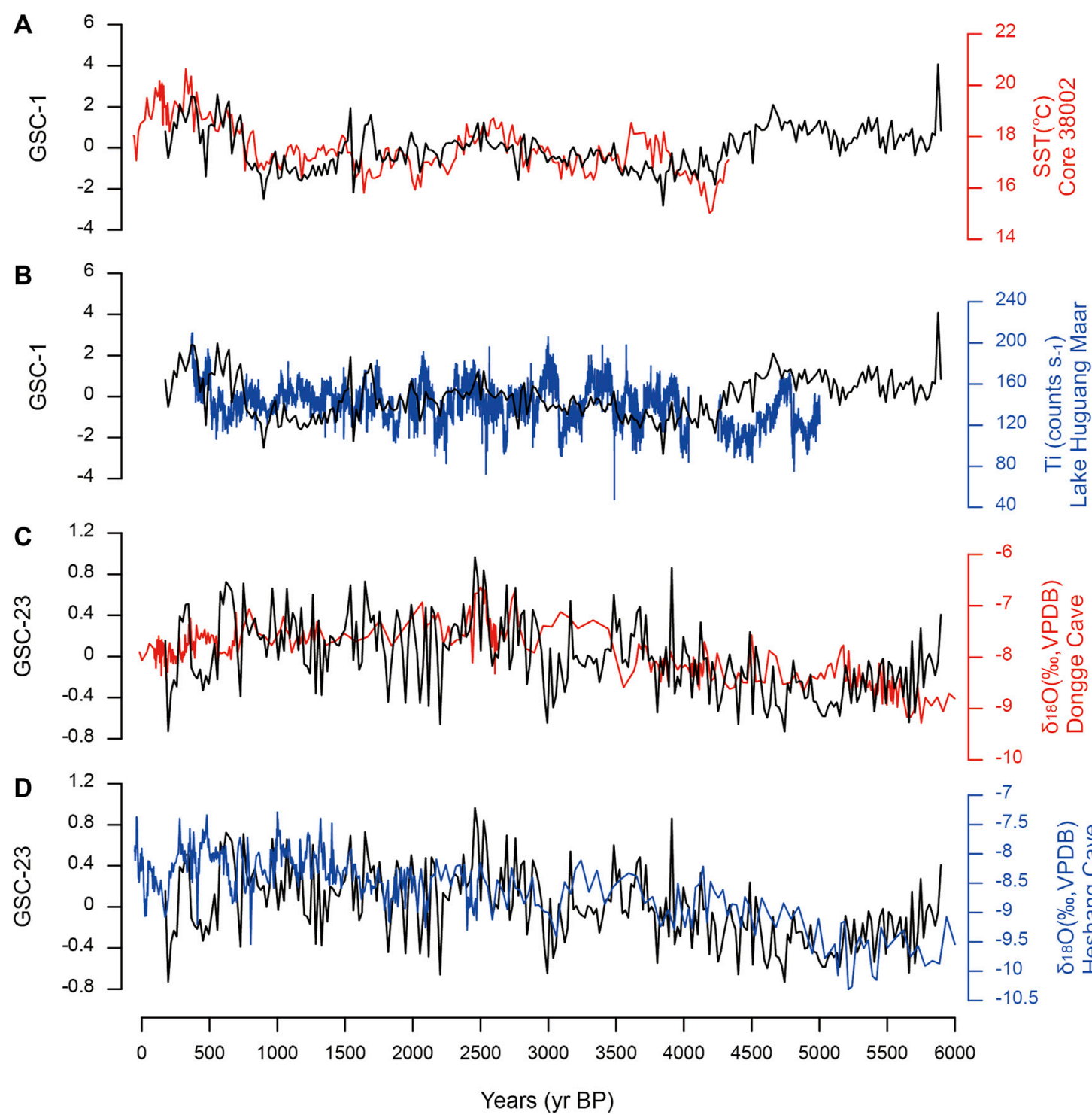

FIGURE 5 | Comparison between various paleoenvironmental proxies since 6,000 years BP: (A) the GSC-1 curve and sea surface temperature (SST) records of sediment core 38,002 in the North Yellow Sea (Zhang et al., 2019), (B) the GSC-1 curve and Ti content records of Lake Huguang Maar (Yancheva et al., 2007), and (C,D) the GSC-23 curve and stalagmite $\delta^{18} \mathrm{O}$ series of Heshang Cave (Hu et al., 2008) and Dongge Cave (Dykoski et al., 2005), indicating EASM intensity.

M38002 from the North Yellow Sea (Zhou et al., 2012) and the grain size VPCA results $(10-40 \mu \mathrm{m})$ of core B60 from the Bohai Sea (Lyu et al., 2020) were extracted as proxies for the EASM, whereas in a record of the EAWM, a sandy component contributes substantially to sediment grain size variation (Qiao et al., 2011; Hu et al., 2012; Zhang S. et al., 2020). We chose the grain size VPCA results of core ZY-1 from the SYS (Hu et al., 2012) and core B60 for comparison with our results (Figure 4). The same structure of data is evident between GSC-1 of core HS2 and F1 of core ZY-1, which was a proxy for the EAWM. The same structure of data also exists between GSC-2 of core HS2 and G-2 of core B60, as well as GSC-3 and G-1, GSC-3 and F2 of core ZY-1. It is also confirmed that G-12 of core $\mathrm{B} 60$ (combination of G-1 and G-2 according to their variance percentages) is a proxy for the EASM, F2 of core $\mathrm{ZY}-1$ is speculated to reflect sedimentary processes in summer. Thus, we conclude that GSC-1 and GSC-23 of core HS2 could be used as proxies for the EAWM and the EASM, respectively. Furthermore, we find that GSC-2 of core HS2 has the same factor loadings in different grain sizes as G-2 of core B60, while the grain size of GSC- 3 is finer than that of G- 1 of core $\mathrm{B} 60$. The fine part plays a dominant role in GSC-2, which represent the weaker hydrodynamic conditions in summer. Through the comparison between GSC-3, F2 and G-1, considering the distance from the Yellow River Estuary (the main source area), it is consistent with the characteristics that the grain size gradually becomes finer after long-distance transportation. Thus, we infer that GSC-2 of core HS2 might represent 


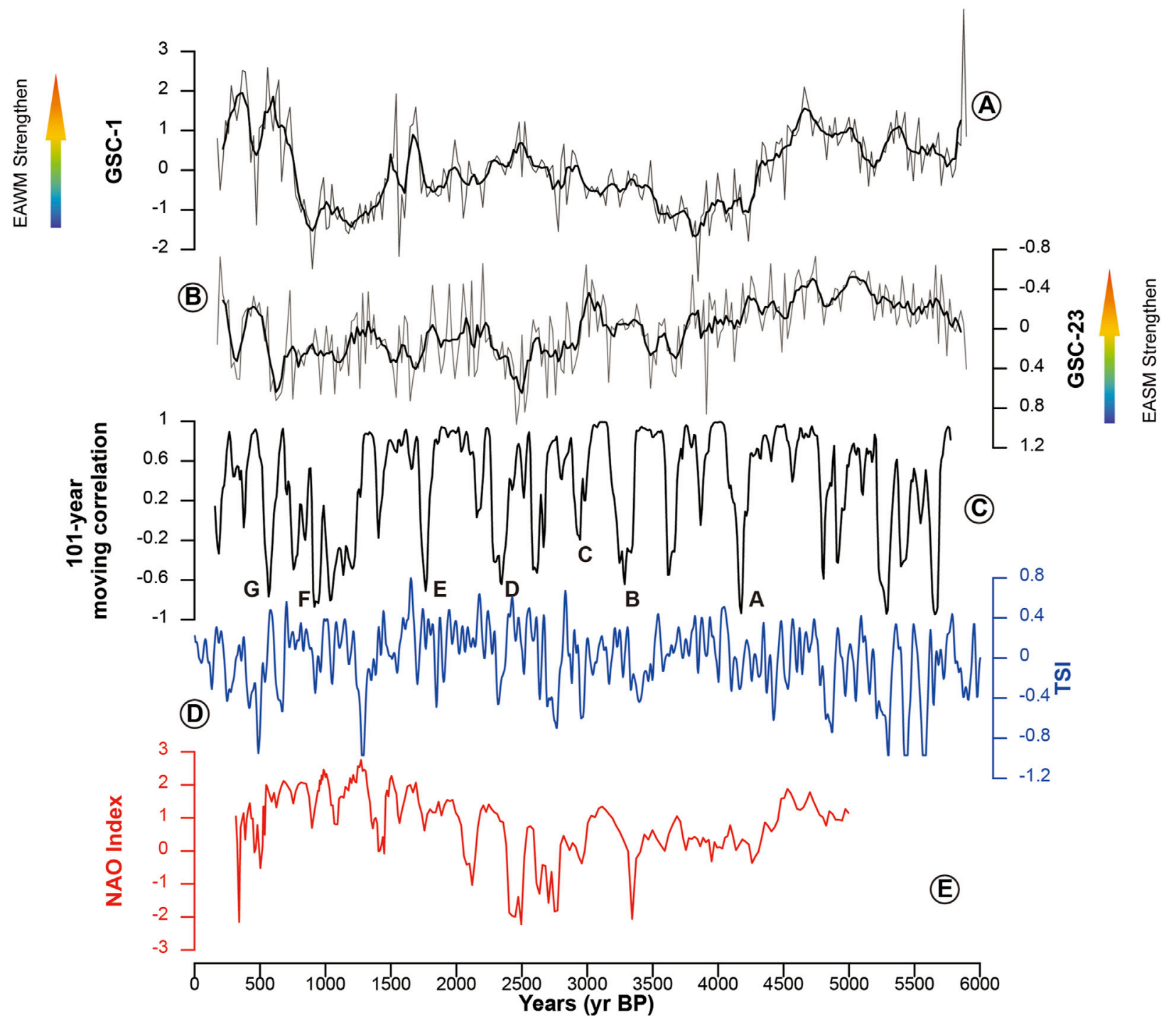

FIGURE 6 | (A,B) Variations of the EASM and the EAWM. The black lines represent the 5-point running average. (C) The 101-years moving correlation between the EASM and the EAWM (capital letters represent the times when certain ancient Chinese regimes were established, i.e., A: Xia Dynasty, B: Shang Dynasty, C: Eastern Zhou Dynasty, D: Han Dynasty, E: Xin Dynasty, F: Ming Dynasty, and G: Qing Dynasty). (D) Total solar irradiance (Steinhilber et al., 2009). (E) North Atlantic Oscillation index reconstructed from Lake SS1220 (Olsen et al., 2012).

sedimentary dynamics, and that GSC-3 represents river supply in summer.

In East Asia, a stronger EASM often brings increased precipitation. This can lead to augmentation of the transport capacity of rivers, which in turn leads to increase in both the sediment supply and the grain size values in the SYS. Given that the coarse part indicates negative loading in GSC-2 and GSC-3, but the fine part indicates positive loading, the low (high) values indicate greater (less) impact of coarse part, thus denote a strong (weak) EASM. In winter, the sedimentary processes are dominated mainly by the EAWM. A stronger EAWM would lead to resuspension of more coarse sediment and to an increase of the suspended sediment concentration. Meanwhile, the YSCC and YSWC would also both be strengthened by a stronger
EAWM, which would lead to enhancement of the transport of the coarser part to the central mud area. Given that the coarse part indicates positive loading in GSC-1, the low (high) values denote a weak (strong) EAWM. In summary, of the factors extracted by VPCA, we conclude that GSC-1 and GSC-23 could be used as proxies for the EAWM and the EASM, respectively.

To validate our inference, we compared our proxies with other published proxies of the EAM (Figure 5). It can be seen that our proxy for the EASM (GSC-23) has reasonable correspondence with stalagmite $\delta^{18} \mathrm{O}$ from Heshang Cave (Hu et al., 2008) and Dongge Cave (Dykoski et al., 2005), which are generally accepted as proxies for the EASM. Lower (higher) values of stalagmite $\delta^{18} \mathrm{O}$ that reflect an enhanced (a weakened) EASM correspond to lower 
(higher) values of GSC-23. Additionally, GSC-1 has reasonable correspondence with both the $\mathrm{Ti}$ content records from Lake Huguang Maar (Yancheva et al., 2007) and the sea surface temperature (SST) records from sediment core 38,002 in the North Yellow Sea (Zhang et al., 2019). The Ti content records could be used as an indicator of the and Zhou et al. (2012) have suggested that SST records from the Yellow Sea reflect the intensity of the YSWC, which is controlled by the EAWM. Thus, the SST records could also be used as an indicator of the EAWM. Higher (lower) values of Ti content and SST that reflect an enhanced (a weakened) EAWM correspond to higher (lower) values of GSC-1. Moreover, we compared our proxies with proxies from core $\mathrm{ZY}-1$ and B60, and proxies documented in more recent studies in central mud area in the South Yellow Sea and nearby regions (Hu et al., 2012; Li and Morrill, 2014; Lyu et al., 2020; Wang et al., 2020; Chen et al., 2021; Zhong et al., 2021), the results showed that there are corresponding relationships between proxies of EASM and EAWM, respectively (Supplementary Figure S1).

Using the proxies, we recovered the variability of the EAM and confirmed the main factor controlling the sedimentary process on the continental shelves of the SYS. Generally, the intensity of both the EASM and the EAWM has shown a fluctuating trend of decrease since approximately 6,000 years BP. Moreover, EAWM intensity can be divided into three periods: strong and relatively stable during approximately 6,000-4,000 years BP, weakened during approximately 4,000-700 years BP, and strong and highly fluctuating since approximately 700 years BP. Conversely, EASM intensity can be divided into just two parts: strong and relatively stable during approximately 6,000-3,700 years BP (similar to the EAWM), and weakened and highly fluctuating since approximately 3,700 years BP.

\section{Relationship Between the East Asian Winter Monsoon and the East Asian Summer Monsoon and Possible Paleoenvironmental Mechanisms}

The nature of the relationship between the EASM and the EAWM during the Holocene remains controversial. One of the main reasons for this uncertainty is the lack of an appropriate archive that could represent the intensity of the two monsoon systems simultaneously (Ge et al., 2017). The proxies for the EASM and the EAWM extracted from the same sedimentary record of core HS2, which remove the influence of dating, provide an excellent opportunity to test their relationship. In this study, the evolutionary history of the EASM and the EAWM showed a similar downward trend on the millennial timescale (Figures 6A,B); however, on the centennial timescale, their relationship was mostly anticorrelated (Figures 6A,B). This finding supports the results of Zhou and Zhao (2009), who concluded that the variability of the EAM during the Holocene was more complex than the simple antiphase relationship between the EASM and the EAWM that has been assumed previously (Xiao et al., 1995; Yancheva et al., 2007).

Moving correlation techniques have been applied widely in the field of climate research (Xu et al., 1997; Zong et al., 2010; Lyu et al., 2020) After comparison of various methods, we chose the 101-years moving correlation between the EAWM (GSC-1) and the EASM (GSC-23) to examine the relationship with global climate change. In addition, we also explored the driving factors of the relationship between the EASM and the EAWM and found reasonable correlation with the total solar irradiance reconstructed from ice cores (Steinhilber et al., 2009) (Figure 6D).

The results showed positive correlation of the value of total solar irradiance to the value of the correlation between the EASM and the EAWM, i.e., high (low) intensity of solar radiation corresponded to negative (positive) correlation between the EASM and the EAWM. Previous studies (Yan et al., 2011; Zhou et al., 2011; Li and Xu, 2016; Li Y. et al., 2016; Xiao and Huo, 2016) have suggested that the EAM is caused by the thermal difference between land and sea. When solar radiation is strong in summer (winter), the thermal difference between land and sea increases (reduces) owing to the faster rate of increase (slower rate of reduction) of the land surface temperature, which leads to the strengthening (weakening) of the EASM (EAWM). Thus, we can conclude that the negative correlation between the EASM and the EAWM is controlled by strong solar radiation. However, we believe that the weakening of solar radiation diminishes the contribution of solar radiation to the thermal difference between land and sea, which in turn leads to the weakening of its ability to control the intensity of the EASM and EAWM. Therefore, without the regulation of strong solar radiation, the EAM exhibits the original correlation, i.e., positive correlation between the EASM and the EAWM, which supports the conclusions of many previous studies (Chen et al., 2000; Yan et al., 2003; Yan et al., 2011).

We also found that the North Atlantic Oscillation (NAO) correlated negatively with the relationship between the EASM and the EAWM (Figure 6E). Previous studies have identified strong links between the EAM system and the NAO; however, these links can change substantially depending on the phase and intensity of the NAO (Sung et al., 2006; Jia and Lin, 2011; Qiao and Feng, 2016; Zuo et al., 2016). Ignoring dating errors, we believe that the NAO has a distinct modulating effect on the relationship between the EASM and the EAWM, particularly the positive correlation during significantly positive NAO phases (Figure 6E). Thus, we conclude that when solar radiation is weak, the correlation between the EASM and the EAWM is modulated by the NAO.

\section{Influence of the East Asian Monsoon on Ancient Civilizations}

We used the 101-years moving correlations between the EAWM (GSC-1) and the EASM (GSC-23) to examine the relationship with the evolution of ancient Chinese civilizations.

Through comparison with a table of Chinese historical dynasties, we found that the correlation between the EASM and the EAWM correspond to the fall or establishment of certain dynasties (Figure 6C). Moreover, all the dynasties represnted by letters in Figure 6C had a similar background of an arid climate and a peasant uprising. Peasant uprisings that 
TABLE 1 | $\mathrm{AMS}^{14} \mathrm{C}$ ages and calendar ages of core HS2.

\begin{tabular}{|c|c|c|c|}
\hline Depth (cm) & Conventional ${ }^{14} \mathrm{C}$ age (a BP) & Calendar age (cal a BP) & $2 \delta$ age range (cal a BP) \\
\hline 86-90 & $2,430 \pm 30$ & 2,161 & $1996-2,325$ \\
\hline $136-138$ & $3,250 \pm 30$ & 3,169 & 2,986-3,352 \\
\hline $186-188$ & $3,880 \pm 30$ & 3,957 & $3,761-4,152$ \\
\hline $236-238$ & $4,900 \pm 30$ & 5,316 & $5,114-5,514$ \\
\hline 286-288 & $5,890 \pm 30$ & 6,404 & $6,256-6,551$ \\
\hline
\end{tabular}

cause regime change often happen when people have experienced prolonged periods of serious drought. Thus, we infer that sustained and serious drought occurs in China as a result of positive correlation between the EASM and the EAWM, rather than simply as the consequence of the role of the EASM. Furthermore, we found positive correlation between the EASM and the EAWM at approximately 4,200 years BP that corresponds to the 4.2-ka cooling event recorded in historical archives (Zhang X. et al., 2020). Previous studies have shown that the 4.2-ka cooling event, with the background of a population explosion in the Holocene Warm Period, promoted the formation of the Chinese civilization (Wu and Liu, 2001; Wang, 2005; Ma et al., 2008). On this basis, our results showed that the EASM and the EAWM weakened simultaneously during 4,700-4,000 years BP. Thus, the concentration of the population in Central China caused by the EAWM and the flooding caused by the EASM led to the establishment of the Xia Dynasty, which is regarded symbolically as the beginning of the Chinese civilization.

\section{CONCLUSION}

Through establishment of an age model and grain size analysis, we extracted proxies for the EASM and the EAWM, and we investigated the main factors controlling the sedimentary dynamics in the SYS and the relationship between the EASM and the EAWM. Results suggested that the intensity of both the EASM and the EAWM showed a fluctuating trend of decrease after approximately 6,000 years BP. It was established that the intensity of the EAWM could be divided into three periods: strong and relatively stable during approximately 6,000-40,000 years BP, weakened during approximately 4,000-700 years BP, and strong and highly fluctuating since approximately 700 years BP. Conversely, the EASM intensity could be divided into only two parts: strong and relatively stable during approximately 6,000-3,700 years BP, and weakened and highly fluctuating since approximately 3,200 years BP.

The evolutionary history of the EASM and the EAWM showed a similar downward trend at the millennial timescale; however, on the centennial timescale, their relationship was mostly anticorrelated. Moreover, it was determined that periods of positive correlation usually coincided with the fall or establishment of ancient dynasties on the Central Plains of China. It was established that negative correlation between the
EASM and the EAWM is controlled by strong solar radiation. Weakening solar radiation leads to weakening of the ability to regulate the correlation between the EASM and the EAWM, at which time the NAO plays a modulating role.

\section{DATA AVAILABILITY STATEMENT}

The original contributions presented in the study are included in the article/Supplementary Material, further inquiries can be directed to the corresponding author.

\section{AUTHOR CONTRIBUTIONS}

Conceptualization, SC; methodology, WL and TF; formal analysis, WL, ZH, YT, GC, and XX; original draft preparation, WL and TF; review and editing, WL and SC. All authors have read and agreed to the published version of the manuscript.

\section{FUNDING}

This research was supported by the National Natural Science Foundation of China (No. U1706214 and 41706068), Basic Scientific Fund for National Public Research Institutes of China (2019Q01), the China Scholarship Council (No. 201906140151).

\section{ACKNOWLEDGMENTS}

The authors thank the captain and crew of the 2015 public cruise of R/V DONG FANG HONG ER HAO organized by the National Natural Science Foundation of China. We thank James Buxton MSc from Liwen Bianji, Edanz Group China (www. liwenbianji.cn/ac), for editing the English text of this manuscript.

\section{SUPPLEMENTARY MATERIAL}

The Supplementary Material for this article can be found online at: https:/www.frontiersin.org/articles/10.3389/feart.2021.689508/ full\#supplementary-material 


\section{REFERENCES}

Beck, J. W., Zhou, W., Li, C., Wu, Z., White, L., Xian, F., et al. (2018). A 550,000year Record of East Asian Monsoon Rainfall from10Be in Loess. Science 360 (6391), 877-881. doi:10.1126/science.aam5825

Chen, W., Graf, H. F., and Ronghui, H. (2000). The Interannual Variability of East Asian Winter Monsoon and its Relation to the Summer Monsoon. Adv. Atmos. Sci. 17 (1), 48-60. doi:10.1007/s00376-000-0042-5

Chen, Y., Lyu, W., Fu, T., Li, Y., and Yi, L. (2021). Centennial Impacts of the East Asian Summer Monsoon on Holocene Deltaic Evolution of the Huanghe River, China. Appl. Sci. 11, 2799. doi:10.3390/app11062799

Cheng, H., Zhang, H., Zhao, J., Li, H., Ning, Y., and Kathayat, G. (2019). Chinese Stalagmite Paleoclimate Researches: A Review and Perspective. Sci. China Earth Sci. 62 (10), 1489-1513. doi:10.1007/s11430-0199478-3

Ding, Z., Liu, T., Rutter, N. W., Yu, Z., Guo, Z., and Zhu, R. (1995). Ice-Volume Forcing of East Asian Winter Monsoon Variations in the Past 800,000 Years. Quat. Res. 44 (2), 149-159. doi:10.1006/qres.1995.1059

Ding, Y., Wang, Z., and Sun, Y. (2008). Inter-decadal Variation of the Summer Precipitation in East China and its Association with Decreasing Asian Summer monsoon.Part I: Observed Evidences. Int. J. Climatol. 28 (9), 1139-1161. doi:10.1002/joc.1615

Ding, Y., Sun, Y., Wang, Z., Zhu, Y., and Song, Y. (2009). Inter-decadal Variation of the Summer Precipitation in China and its Association with Decreasing Asian Summer Monsoon Part II: Possible Causes. Int. J. Climatol. 29 (13), 1926-1944. doi:10.1002/joc. 1759

Ding, D. L., Li, G. X., Xu, J. S., Ding, D., Li, Q., Wang, L. Y., et al. (2017). Evolution of the Asian Monsoon during the Holocene. Earth Sci. Front. 24 (04), 114-123. (in Chinese with English Abstract). doi:10.13745/j.esf.yx.20174-12

Dykoski, C. A., Edwards, R., Cheng, H., Yuan, D., Cai, Y., Zhang, M., et al. (2005). A High-Resolution, Absolute-Dated Holocene and Deglacial Asian Monsoon Record from Dongge Cave, China. Earth Planet. Sci. Lett. 233 (1-2), 71-86. doi:10.1016/j.epsl.2005.01.036

Ge, Q., Xue, Z., Yao, Z., Zang, Z., and Chu, F. (2017). Anti-phase Relationship between the East Asian winter Monsoon and Summer Monsoon during the Holocene? J. Ocean Univ. China 16 (2), 175-183. doi:10.1007/s11802-0173098-x

Hong, Y. T., Wang, Z. G., Jiang, H. B., Lin, Q. H., and Li, H. D. (2001). A 6000-year Record of Changes in Drought and Precipitation in Northeastern China Based on a $\delta 13 \mathrm{C}$ Time Series from Peat Cellulose. Earth Planet. Sci. Lett. 185 (1-2), 111-119. doi:10.1016/s0012-821x(00)00367-8

Hong, Y. T., Hong, B., Lin, Q. H., Shibata, Y., Zhu, Y. X., Leng, X. T., et al. (2009). Synchronous Climate Anomalies in the Western North Pacific and North Atlantic Regions during the Last 14,000 Years. Quat. Sci. Rev. 28 (9-10), 840-849. doi:10.1016/j.quascirev.2008.11.011

Hu, C., Henderson, G. M., Huang, J., Xie, S., Sun, Y., and Johnson, K. R. (2008). Quantification of Holocene Asian Monsoon Rainfall from Spatially Separated Cave Records. Earth Planet. Sci. Lett. 266 (3-4), 221-232. doi:10.1016/ j.epsl.2007.10.015

Hu, B., Yang, Z., Zhao, M., Saito, Y., Fan, D., and Wang, L. (2012). Grain Size Records Reveal Variability of the East Asian Winter Monsoon since the Middle Holocene in the Central Yellow Sea Mud Area, China. Sci. China Earth Sci. 55 (10), 1656-1668. doi:10.1007/s11430-012-4447-7

Huang, R., Chen, J., and Huang, G. (2007). Characteristics and Variations of the East Asian Monsoon System and its Impacts on Climate Disasters in China. Adv. Atmos. Sci. 24 (6), 993-1023. doi:10.1007/s00376-007-0993-x

Jia, X., and Lin, H. (2011). Influence of Forced Large-Scale Atmospheric Patterns on Surface Air Temperature in China. Monthly Weather Rev. 139 (3), 830-852. doi:10.1175/2010mwr3348.1

Kong, G. S., Park, S. C., Han, H. C., Chang, J. H., and Mackensen, A. (2006). Late Quaternary Paleoenvironmental Changes in the Southeastern Yellow Sea, Korea. Quat. Int. 144, 38-52. doi:10.1016/j.quaint.2005.05.011

Li, Y., and Morrill, C. (2014). A Holocene East Asian Winter Monsoon Record at the Southern Edge of the Gobi Desert and its Comparison with a Transient Simulation. Clim. Dyn. 45, 1219-1234. doi:10.1007/s00382014-2372-5
Li, F., and Wang, H. (2012). Predictability of the East Asian Winter Monsoon Interannual Variability as Indicated by the DEMETER CGCMS. Adv. Atmos. Sci. 29 (3), 441-454. doi:10.1007/s00376-011-1115-3

Li, Y., and Xu, L. (2016). Asynchronous Holocene Asian Monsoon Vapor Transport and Precipitation. Palaeogeogr. Palaeoclimatol. Palaeoecol. 461, 195-200. doi:10.1016/j.palaeo.2016.08.024

Li, C., Fu, J., Yi, L., Zhou, X., Wang, S., and Jiang, F. (2015). Millennial-Scale Asian Monsoon Influenced Longjie Lake Evolution during Marine Isotope Stage 3, Upper Stream of Changiiang (Yangtze) River, China. Adv. Meteorol. 2015, 1-10. doi:10.1155/2015/592894

Li, X., Liu, X., He, Y., Liu, W., Zhou, X., and Wang, Z. (2018). Summer Moisture Changes in the Lake Qinghai Area on the Northeastern Tibetan Plateau Recorded from a Meadow Section over the Past 8400 Yrs. Glob. Planet. Change 161, 1-9. doi:10.1016/j.gloplacha.2017.11.016

Li, G., Qiao, L., Dong, P., Ma, Y., Xu, J., Liu, S., et al. (2016). Hydrodynamic Condition and Suspended Sediment Diffusion in the Yellow Sea and East China Sea. J. Geophys. Res. Oceans 121 (8), 6204-6222. doi:10.1002/ 2015jc011442

Li, Y., Zhang, C., and Wang, Y. (2016). The Verification of Millennial-Scale Monsoon Water Vapor Transport Channel in Northwest China. J. Hydrol. 536, 273-283. doi:10.1016/j.jhydrol.2016.03.006

Liu, G., Li, X., Chiang, H.-W., Cheng, H., Yuan, S., Chawchai, S., et al. (2020). On the Glacial-Interglacial Variability of the Asian Monsoon in Speleothem $\delta 18 \mathrm{O}$ Records. Sci. Adv. 6 (7), eaay8189. doi:10.1126/sciadv.aay8189

Liu, J., Shi, X., Liu, Q., Ge, S., Liu, Y., Yao, Z., et al. (2014). Magnetostratigraphy of a Greigitebearing Core from the South Yellow Sea: Implications for Remagnetization and Sedimentation. J. Geophys. Res. Solid Earth 119 (10), 7425-7441. doi:10.1002/2014JB011206

Lyu, W., Yang, J., Fu, T., Chen, Y., Hu, Z., Tang, Y. Z., et al. (2020). Asian Monsoon and Oceanic Circulation Paced Sedimentary Evolution over the Past 1,500 years in the central Mud Area of the Bohai Sea, China. Geol. J. 55 (7), 5606-5618. doi:10.1002/gj. 3758

Ma, C. M., Zhu, C., Zheng, C. G., Wu, C. L., Guan, Y., Zhao, Z. P., et al. (2008). High-resolution Geochemistry Records of Climate Changes since Late-Glacial from Dajiuhu Peat in Shennongiia Mountains, Central China. Chin. Sci. Bull. 53 (S1), 26-37. doi:10.1007/s11434-008-5007-6

McManus, J. (1988). "Grain Size Determination and Interpretation," Techniques in Sedimentology. Editors M. Tucker (Oxford: Blackwell), 63-85.

Olsen, J., Anderson, N. J., and Knudsen, M. F. (2012). Variability of the North Atlantic Oscillation over the Past 5,200 Years. Nat. Geosci. 5 (11), 808-812. doi:10.1038/ngeo1589

Passega, R. (1964). Grain Size Representation by CM Patterns as a Geologic Tool. J. Sediment. Res. 34, 830-847.

Passega, R. (1957). Texture as Characteristic of Clastic Deposition. AAPG Bull., 1952-1984.

Qiao, S., and Feng, G. (2016). Impact of the December North Atlantic Oscillation on the Following February East Asian Trough. J. Geophys. Res. Atmos. 121 (17), 10,074-10,088. doi:10.1002/2016jd025007

Qiao, S., Yang, Z., Liu, J., Sun, X., Xiang, R., Shi, X., et al. (2011). Records of LateHolocene East Asian winter Monsoon in the East China Sea: Key Grain-Size Component of Quartz versus Bulk Sediments. Quat. Int. 230 (1), 106-114. doi:10.1016/j.quaint.2010.01.020

Qiao, S., Shi, X., Wang, G., Zhou, L., Hu, B., Hu, L., et al. (2017). Sediment Accumulation and Budget in the Bohai Sea, Yellow Sea and East China Sea. Mar. Geology. 390, 270-281. doi:10.1016/j.margeo.2017.06.004

Song, Y., Hao, Q., Ge, J., Zhao, D. a., Zhang, Y., Li, Q., et al. (2014). Quantitative Relationships between Magnetic Enhancement of Modern Soils and Climatic Variables over the Chinese Loess Plateau. Quat. Int. 334-335, 119-131. doi:10.1016/j.quaint.2013.12.010

Steinhilber, F., Beer, J., and Fröhlich, C. (2009). Total Solar Irradiance during the Holocene. Geophys. Res. Lett. 36, L19704. doi:10.1029/2009gl040142

Steinke, S., Glatz, C., Mohtadi, M., Groeneveld, J., Li, Q., and Jian, Z. (2011). Past Dynamics of the East Asian Monsoon: No Inverse Behaviour between the Summer and winter Monsoon during the Holocene. Glob. Planet. Change 78 (34), 170-177. doi:10.1016/j.gloplacha.2011.06.006

Stuiver, M., and Reimer, P. J. (1993). Extended 14C Data Base and Revised CALIB 3.0 14C Age Calibration Program. Radiocarbon 35 (1), 215-230. doi:10.1017/ S0033822200013904 
Sun, Y., Clemens, S. C., An, Z., and Yu, Z. (2006). Astronomical Timescale and Palaeoclimatic Implication of Stacked 3.6-Myr Monsoon Records from the Chinese Loess Plateau. Quat. Sci. Rev. 25 (1-2), 33-48. doi:10.1016/ j.quascirev.2005.07.005

Sung, M. K., Kwon, W. T., Baek, H. J., Boo, K. O., Lim, G. H., and Kug, J. S. (2006). A Possible Impact of the North Atlantic Oscillation on the East Asian Summer Monsoon Precipitation. Geophys. Res. Lett. 33 (21). doi:10.1029/ $2006 \mathrm{gl} 1027253$

Thompson, L. G. (1997). Tropical Climate Instability: The Last Glacial Cycle from a Qinghai-Tibetan Ice Core. Science 276 (5320), 1821-1825. doi:10.1126/ science.276.5320.1821

Wang, H., Li, G., Zhang, Y., Liu, Y., Liu, D., Ding, D., et al. (2020). Evolution of Palaeoenvironment of the South Yellow Sea since the Last Deglaciation. J. Ocean Univ. China 19 (4), 827-836. doi:10.1007/s11802-020-4213-y

Wang, K., Zheng, H. B., Maarten, P., and Zheng, Y. (2008). High-resolution Paleoenvironmental Record of the Mud Sediments of the East China Sea Inner Shelf. Mar. Geol. Quat. Geol. 28 (4), 1-10. (in Chinese with English Abstract). doi:10.3724/SP.J.1140.2008.03001

Wang, L., Li, G., Xu, J., Liu, Y., Lu, Q., Ding, D., et al. (2019). Strata Sequence and Paleochannel Response to Tectonic, Sea-Level, and Asian Monsoon Variability Since the Late Pleistocene in the South Yellow Sea. Quat. Res. 1-19. doi:10.1017/ qua.2019.29

Wang, Y., Cheng, H., Edwards, R. L., Kong, X., Shao, X., Chen, S., et al. (2008). Millennial- and Orbital-Scale Changes in the East Asian Monsoon over the Past 224,000 Years. Nature 451 (7182), 1090-1093. doi:10.1038/ nature 06692

Wang, S. W. (2005). Abrupt Climate Change and Collapse of Ancient Civilizations at 2200BC-2000BC. Prog. Nat. Sci. 15 (9), 1094-1099. (in Chinese with English Abstract). doi:10.3321/j.issn:1002-008X.2005.09.010

Wessel, P., Luis, J. F., Uieda, L., Scharroo, R., Wobbe, F., Smith, W. H. F., et al. (2019). The Generic Mapping Tools Version 6. Geochem. Geophys. Geosyst. 20 (11), 5556-5564. doi:10.1029/2019gc008515

Wu, M. C., and Chan, J. C. L. (2005). Observational Relationships between Summer and winter Monsoons over East Asia. Part II: Results. Int. J. Climatol. 25 (4), 453-468. doi:10.1002/joc.1153

Wu, W. X., and Liu, D. S. (2001). 4000 a B.P. Event and its Implications for the Origin of Ancient Chinese Civilization. Quat. Sci. 21 (5), 443-451. (in Chinese with English Abstract). doi:10.3321/j.issn:1001-7410.2001.05.008

Xiang, R., Yang, Z., Saito, Y., Fan, D., Chen, M., Guo, Z., et al. (2008). Paleoenvironmental Changes During the Last 8400 Years in the Southern Yellow Sea: Benthic Foraminiferal and Stable Isotopic Evidence. Mar. Micropaleontol. 67 (1-2), 104-119. doi:10.1016/ j.marmicro.2007.11.002

Xiao, Z. N., and Huo, W. J. (2016). Influences of Solar Activity on Climate: the Spatio-Temporal Selectivity of the Amplification Process. Adv. Meteorol. Sci. Technol. 6 (3), 141-147. (in Chinese with English Abstract). doi:10.3969/ j.issn.2095-1973.2016.03.019

Xiao, J., Porter, S. C., An, Z., Kumai, H., and Yoshikawa, S. (1995). Grain Size of Quartz as an Indicator of Winter Monsoon Strength on the Loess Plateau of Central China during the Last 130,000 Yr. Quat. Res. 43 (1), 22-29. doi:10.1006/ qres.1995.1003

Xiao, S., Li, A., Liu, J. P., Chen, M., Xie, Q., Jiang, F., et al. (2006). Coherence between Solar Activity and the East Asian winter Monsoon Variability in the Past 8000 Years from Yangtze River-Derived Mud in the East China Sea. Palaeogeogr. Palaeoclimatol. Palaeoecol. 237 (2-4), 293-304. doi:10.1016/ j.palaeo.2005.12.003

Xing, L., Zhao, M., Zhang, H., Zhao, X., Zhao, X., Yang, Z., et al. (2012). Biomarker Evidence for Paleoenvironmental Changes in the Southern Yellow Sea over the Last 8200 Years. Chin. J. Ocean. Limnol. 30 (1), 1-11. doi:10.1007/s00343-012$1045-7$

Xu, J. J., Zhu, Q. G., and Shi, N. (1997). The Interaction of East Asian Winter Monsoon with ENSO Cycle and their Interdecadal Variations in Last Century. Sci. Sin. 21, 641-648. doi:10.3878/j.issn.1006-9895.1997.06.01

Yan, H. M., Duan, W., and Xiao, Z. N. (2003). A Study on Relation between East Asian Winter Monsoon and Climate Change during Raining Season in China. J. Trop. meteorology 19 (4), 367-376. (in Chinese with English Abstract). doi:10.3969/j.issn.1004-4965.2003.04.004
Yan, H., Yang, H., Yuan, Y., and Li, C. (2011). Relationship between East Asian Winter Monsoon and Summer Monsoon. Adv. Atmos. Sci. 28 (6), 1345-1356. doi:10.1007/s00376-011-0014-y

Yancheva, G., Nowaczyk, N. R., Mingram, J., Dulski, P., Schettler, G., Negendank, J. F. W., et al. (2007). Influence of the Intertropical Convergence Zone on the East Asian Monsoon. Nature 445 (7123), 74-77. doi:10.1038/nature05431

Yang, J., Li, G., Liu, Y., Dada, O. A., Zhao, M., Ma, Z., et al. (2018). Evolution of Sedimentary Mode Since Pleistocene in the Central South Yellow Sea, China, Based on Seismic Stratigraphy Analysis. Quta. Int. 482, 157-170. doi:10.1016/ j.quaint.2018.03.018

Yang, S., and Youn, J. (2007). Geochemical Compositions and Provenance Discrimination of the central South Yellow Sea Sediments. Mar. Geology. 243 (1-4), 229-241. doi:10.1016/j.margeo.2007.05.001

Yang, S. Y., Jung, H. S., Lim, D. I., and Li, C. X. (2003). A Review on the Provenance Discrimination of Sediments in the Yellow Sea. Earth-Science Rev. 63 (1-2), 93-120. doi:10.1016/s0012-8252(03)00033-3

Yuan, D., and Hsueh, Y., 2010. Dynamics of the Cross-Shelf Circulation in the Yellow and East China Seas in winter., 57(19-20): 1745-1761. doi:10.1016/ j.dsr2.2010.04.002

Zhang, D. e., and Lu, L. (2007). Anti-correlation of Summer/winter Monsoons? Nature 450 (7168), E7,8-E8-E9. doi:10.1038/nature06338

Zhang, Y., Li, G., Guo, H., Yong, L., Wang, H., Xu, J., et al. (2018). Sedimentary Characteristics of the Second Marine Layer During the Late Marine Isotope Stage 3 in Southern Yellow Sea and Their Response to the East Asian Monsoon. J. Ocean Univ. China 17 (5), 1103-1113. doi:10.1007/s11802018-3527-5

Zhang, Y., Zhou, X., He, Y., Jiang, Y., Liu, Y., Xie, Z., et al. (2019). Persistent Intensification of the Kuroshio Current during Late Holocene Cool Intervals. Earth Planet. Sci. Lett. 506, 15-22. doi:10.1016/ j.epsl.2018.10.018

Zhang, S., Xiao, J., Xu, Q., Wen, R., Fan, J., Huang, Y., et al. (2020). Contrasting Impacts of the 8.2- and 4.2-ka Abrupt Climatic Events on the Regional Vegetation of the Hulun Lake Region in north-eastern China. J. Quat. Sci 35 (6), 831-840. doi:10.1002/jqs.3231

Zhang, X., Fan, D., Tian, Y., Sun, Z., Zhai, B., Liu, M., et al. (2020). Quantitative Reconstruction of the East Asian Winter Monsoon Evolution over the Past 100 years: Evidence from High-Resolution Sedimentary Records of the Inner continental Shelf of the East China Sea. The Holocene 30, 1053-1062. doi:10.1177/0959683620908661

Zhao, X., Tao, S., Zhang, R., Zhang, H., Yang, Z., and Zhao, M. (2013). Biomarker Records of Phytoplankton Productivity and Community Structure Changes in the Central Yellow Sea Mud Area during the Midlate Holocene. J. Ocean Univ. China 12 (4), 639-646. doi:10.1007/s11802013-2271-0

Zheng, Y., Kissel, C., Zheng, H. B., Laj, C., and Wang, K. (2010). Sedimentation on the Inner Shelf of the East China Sea: Magnetic Properties, Diagenesis and Paleoclimate Implications. Mar. Geology. 268 (1-4), 34-42. doi:10.1016/ j.margeo.2009.10.009

Zhong, F., Xiang, R., Zhang, L., Yang, Y., Zhao, M., and Zhou, L. (2021). A Synthesized Study of the Spatiotemporal Evolution of Central Yellow Sea Mud Depositional Processes during the Holocene. Front. Earth Sci. 9, 687344. doi: $10.3389 /$ feart.2021.687344

Zhou, B., and Zhao, P. (2009). Inverse Correlation between Ancient winter and Summer Monsoons in East Asia? Chin. Sci. Bull. 54 (20), 3760-3767. doi:10.1007/s11434-009-0583-7

Zhou, T., Li, B., Man, W., Zhang, L., and Zhang, J. (2011). A Comparison of the Medieval Warm Period, Little Ice Age and 20th century Warming Simulated by the FGOALS Climate System Model. Chin. Sci. Bull. 56 (28-29), 3028-3041. doi:10.1007/s11434-011-4641-6

Zhou, X., Sun, L., Huang, W., Cheng, W., and Jia, N. (2012). Precipitation in the Yellow River Drainage basin and East Asian Monsoon Strength on a Decadal Time Scale. Quat. Res. 78 (3), 486-491. doi:10.1016/ j.yqres.2012.07.008

Zhou, C., Dong, P., and Li, G. (2015). Hydrodynamic Processes and Their Impacts on the Mud deposit in the Southern Yellow Sea. Mar. Geology. 360, 1-16. doi:10.1016/j.margeo.2014.11.012 
Zong, H. F., Chen, L. T., and Zhang, Q. Y. (2010). The Instability of the Interannual Relationship Between ENSO and the Summer Rainfall in China. Chin. J. Atmos. Sci. 34, 184-192. doi:10.3878/j.issn.10069895.2010.01.17

Zuo, J., Ren, H.-L., Li, W., and Wang, L. (2016). Interdecadal Variations in the Relationship between the Winter North Atlantic Oscillation and Temperature in South-Central China. J. Clim. 29 (20), 7477-7493. doi:10.1175/jcli-d-150873.1

Conflict of Interest: The authors declare that the research was conducted in the absence of any commercial or financial relationships that could be construed as a potential conflict of interest.
Publisher's Note: All claims expressed in this article are solely those of the authors and do not necessarily represent those of their affiliated organizations, or those of the publisher, the editors and the reviewers. Any product that may be evaluated in this article, or claim that may be made by its manufacturer, is not guaranteed or endorsed by the publisher.

Copyright (c) $2021 \mathrm{Lyu}, \mathrm{Fu}, \mathrm{Hu}$, Tang, Chen, Xu, Chen and Chen. This is an openaccess article distributed under the terms of the Creative Commons Attribution License (CC BY). The use, distribution or reproduction in other forums is permitted, provided the original author(s) and the copyright owner(s) are credited and that the original publication in this journal is cited, in accordance with accepted academic practice. No use, distribution or reproduction is permitted which does not comply with these terms. 